\title{
International Psychogeriatrics paper of the year 2014: a new tradition and the first candidate for a 2024 paper of the decade?
}

In 2014, the International Psychogeriatric Association (IPA) celebrated the fact that IPA's flagship scientific journal International Psychogeriatrics (IPG) has matured, attaining 25 years of existence since its foundation in 1989. The IPG editorial team introduced several new features in the 2014 issues to celebrate this significant quarter century milestone. One of them was the new "paper of the month" category. Following an internal selection process amongst the editorial team, who ranked available accepted papers focusing on their scientific quality and clinical relevance each month, one paper was selected as paper of the month from the categories "original research articles" and "reviews". This resulted in 12 papers of the month, of which eight were original research articles and four were reviews or meta-analyses. Each paper of the month was accompanied by a short commentary highlighting its importance, written either by an editorial team member, one of the reviewers of the paper, or an external international expert on the topic of the paper. The editorial team aimed to highlight various psychogeriatric topics, so there are papers covering the wide spectrum of cognitive impairment, from risk factors such a hippocampal atrophy (Ferrarini et al., 2014) and traumatic brain injury (Gilbert et al., 2014), via transition between diagnostic categories on the cognitive continuum (Ellis et al., 2014) to variations in symptom expression (Rockwood et al., 2014) and apathy (Theleritis et al., 2014) to exercise interventions for people with Alzheimer's disease (AD) (Farina et al., 2014) or antipsychotic use for patients with dementia living in residential care (Kleijer et al., 2014). Other papers reported on topics relevant to the aging process in general, such as neuroplasticity (Valkanova et al., 2014), loneliness (Yan et al., 2014) or attitudes to aging (Shenkin et al., 2014). Other psychogeriatric topics covered were delirium (Ritchie et al., 2014) and geriatric depression (Steffens et al., 2014). In the international spirit of IPA, authors of the 12 papers come from Australia, Canada China, Greece, Germany, Italy, Mexico, the Netherlands, Switzerland, the UK, and the USA. From those 12 papers an IPG paper of the year 2014 was selected with the help of three independent reviewers: Dr Doh Kwan Kim from South Korea, Dr Gill Livingston from the UK, and Dr Daniel Weintraub from the USA. Our three reviewers ranked all 12 papers of the month independently from each other and the highest ranked paper overall was "The association of traumatic brain injury with rate of progression of cognitive and functional impairment in a population-based cohort of Alzheimer's disease: the Cache County Dementia Progression Study" by Mac Gilbert, Christine Snyder, Chris Corcoran, Maria C. Norton, Constantine G. Lyketsos, and JoAnn T. Tschanz. The reviewers emphasized that traumatic brain injury (TBI) is recognized as an important risk factor for $\mathrm{AD}$ which needs more research, and that the study by Gilbert et al. contributes important new knowledge to the area with the specific strength of reporting longterm follow up. In this context, we refer to the excellent commentary on the paper of the year by Dr David Sharp (Sharp, 2014), which was published alongside the paper of the year when it was paper of the month in the October 2014 issue.

The Editorial Team has decided to continue the paper of the month and the paper of the year categories beyond the birthday year of 2014, as we view them as good initiatives to further develop the journal and as a good opportunity to highlight for the readers of IPG some of the excellent contributions the journal receives. With the help of our publisher, Cambridge University Press, we encouraged the authors of the 12 papers of the month to contribute more information about their studies and were delighted that the majority were happy to provide this via blogs. We thank and congratulate the authors of the 12 papers, the authors of the 12 commentaries and the 3 independent reviewers for helping to establish this new category.

We conclude by congratulating the authors of the paper of the year 2014 and note that in ten years of time they will have a one in ten chance of being selected as the paper of the decade! 


\section{Conflict of interest}

None.

NiCOLA T. LAUTENSCHLAGER ${ }^{1,2}$ AND DAVID AMES ${ }^{1,3}$, Editor-in-Chief and Immediate

Past Editor-in-Chief On behalf of the Editorial

Team of International Psychogeriatrics

${ }^{1}$ Academic Unit for Psychiatry of Old Age, St. Vincent's Health, Department of Psychiatry, University of Melbourne, Melbourne, Victoria, Australia

${ }^{2}$ School of Psychiatry \& Clinical Neurosciences \&

Western Australian Centre for Health \& Ageing, University of Western Australia, Crawley WA, Perth, Australia

${ }^{3}$ National Ageing Research Institute (NARI), Parkville, Victoria, Australia Email: nicolatl@unimelb.edu.au

\section{References}

Ellis, K. A. et al. (2014). Rates of diagnostic transition and cognitive change at 18-month follow-up among 1,112 participants in the Australian imaging, biomarkers and lifestyle flagship study of ageing (AIBL). International Psychogeriatrics, 26, 543-554.

Farina, N., Rusted, J. and Tabet, N. (2014). The effect of exercise interventions on cognitive outcome in Alzheimer's disease: a systematic review. International Psychogeriatrics, 26, 9-18.

Ferrarini, L. et al. (2014). Hippocampal atrophy in people with memory deficits: results from the population-based IPREA study. International Psychogeriatrics, 26, 1067-1081.

Gilbert, M., Snyder, C., Corcoran, C., Norton, M.C., Lyketsos, C.G. and Tschanz, J.T. (2014). The association of traumatic brain injury with rate of progression of cognitive and functional impairment in a population-based cohort of Alzheimer's disease: the cache county dementia progression study. International Psychogeriatrics, 26, 1593-1601.
Kleijer, B. C. et al. (2014). Variability between nursing homes in prevalence of antipsychotic use in patients with dementia. International Psychogeriatrics, 26, 363371.

Ritchie, C. W., Newman, T. H., Leurent, B. and Sampson, E. L. (2014). The association between C-reactive protein and delirium in 710 acute elderly hospital admissions. International Psychogeriatrics, 26, 717-724.

Rockwood, K., Fay, S., Hamilton, L., Ross, E. and Moorhouse, P. (2014). Good days and bad days in dementia: a qualitative chart review of variable symptom expression. International Psychogeriatrics, 26, 12391246.

Sharp, D. (2014). The association of traumatic brain injury with rate of progression of cognitive and functional impairment in a population-based cohort of Alzheimer's disease: the cache county dementia progression study by Gilbert et al. Late effects of traumatic brain injury on dementia progression. International Psychogeriatrics, 26, 1591-1592.

Shenkin, S.D., Laidlaw, K., Allerhand, M., Mead, G.E., Starr, J.M. and Deary, I.J. (2014). Life course influences of physical and cognitive function and personality on attitudes to aging in the Lothian Birth Cohort 1936. International Psychogeriatrics, 26, 1417-1430.

Steffens, D. C., McQuoid, D. R. and Potter, G. G. (2014). Amnestic mild cognitive impairment and incident dementia and Alzheimer's disease in geriatric depression. International Psychogeriatrics, 26, 2029-2036.

Theleritis, C., Politis, A., Siarkos, K. and Lyketsos, C. G. (2014). A review of neuroimaging findings of apathy in Alzheimer's disease. International Psychogeriatrics, 26, 195-207.

Valkanova, V., Rodriguez, R. E. and Ebmeier, K. P. (2014). Mind over matter - what do we know about neuroplasticity in adults? International Psychogeriatrics, 26, 891-909.

Yan, Z., Yang, X., Wang, L., Zhao, Y. and Yu, L. (2014). Social change and birth cohort increase in loneliness among Chinese older adults: a cross-temporal meta-analysis, 1995-2011. International Psychogeriatrics, 26, 1773-1781. 